\title{
Benzylic Ammonium Ylide Mediated Epoxidations
}

\author{
Lukas Roiser ${ }^{a}$ \\ Raphaël Robiette*b \\ Mario Waser*a \\ a Institute of Organic Chemistry, Johannes Kepler University \\ Linz, Altenbergerstraße 69, 4040 Linz, Austria \\ mario.waser@jku.at \\ b Institute of Condensed Matter and Nanosciences, Université \\ catholique de Louvain, Place Louis Pasteur 1 box L4.01.02. \\ 1348 Louvain-la-Neuve, Belgium \\ raphael.robiette@uclouvain.be
}

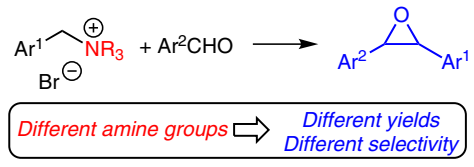

Received: 31.03.2016

Accepted after revision: 22.05.2016

Published online: 15.06 .2016

DOI: 10.1055/s-0035-1562344; Art ID: st-2016-b0225-I

License terms: CC $(A)$

Abstract A high yielding synthesis of stilbene oxides using ammonium ylides has been developed. It turned out that the amine leaving group plays a crucial role as trimethylamine gives higher yields than DABCO or quinuclidine. The amine group also influences the diastereoselectivity, and detailed DFT calculations to understand the key parameters of these reactions have been carried out.

Key words epoxides, ylides, diastereoselectivity, DFT calculations, diazo compounds

Onium ylides are versatile reagents for (dia)stereoselective epoxide, aziridine, and cyclopropane syntheses. ${ }^{1-10}$ In contrast to sulfonium ylides, which are frequently used for a variety of three-ring forming reactions, ${ }^{3}$ ammonium ylides have been less routinely used in the past. ${ }^{4-8}$ This is mainly because of the weaker leaving group ability of the amine group as compared to their sulfur analogues. ${ }^{10}$

We have recently succeeded in developing a high yielding and highly trans-selective epoxidation reaction using amide-stabilised ammonium salts $\mathbf{1}$ as ylide precursors (Scheme 1). ${ }^{7}$ Key to success in this transformation was the use of trimethylamine as the amine leaving group of choice, which was clearly superior to other tertiary amines such as $\mathrm{DABCO}$, quinuclidine, or triethylamine. Expanding the application scope of this operationally simple method we became interested in the synthesis of stilbene oxides $\mathbf{5}$, starting from benzylic ammonium salts 4 (Scheme 1). This transformation has been reported in the past using DABCO and quinuclidine as the amino group. ${ }^{5}$ However, it was found that the nature of the leaving group, as well as the electronic properties of the aryl group of the benzylic ammonium salt $\mathbf{4}$ play a crucial role hereby. While electron- rich or phenyl-based ammonium salts $\mathbf{4}$ gave epoxides $\mathbf{5}$ in up to $40 \%$ yields only (with a cis/trans ratio depending on the leaving group ability), more stabilised ylides (with electron-withdrawing aryl substituents) allowed for higher yields and higher trans selectivities. ${ }^{5}$ Based on computational results, Aggarwal and co-workers explain the observed generally low yields by the high barrier to elimination, which is a consequence of the poor leaving group ability of the amine group. ${ }^{5 c}$ They also rationalize the observed variations in diastereoselectivity according to the nature of the substrate by the degree of reversibility in betaine formation: reaction of stabilized ylides (substituted by electron-poor aryl groups) lead to reversibility of betaine formation and high trans selectivity, whilst groups that destabilize the ylide (electron-rich aryl groups) or reduce the barrier to ring closure (better amine leaving group) lead to reduced reversibility and lower diastereoselectivity. ${ }^{11}$

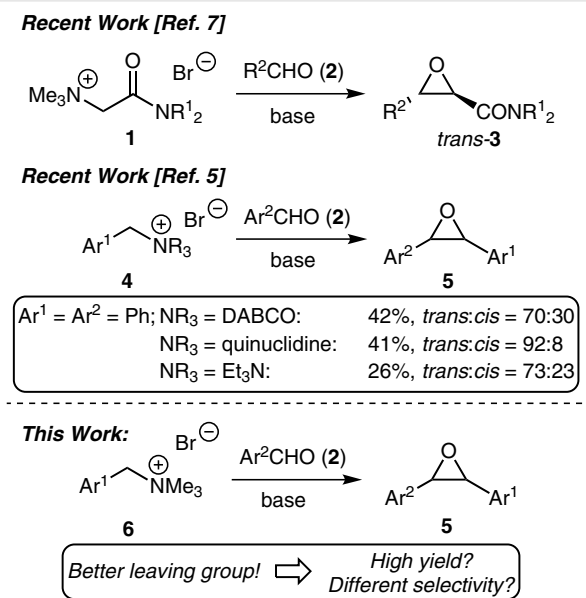

Scheme 1 Recent results in the field of ammonium ylide mediated epoxidations and targeted (high yielding) synthesis of stilbene oxides $\mathbf{5}$ with trimethylamine-based ammonium salts $\mathbf{6}$. 
Based on these observations and our excellent previous experience with trimethylamine-based ammonium salts, ${ }^{7}$ we became interested in investigating if the beneficial effect of this superior leaving group also holds for the synthesis of stilbene oxides $\mathbf{5}$ and evaluating the effect of $\mathrm{Me}_{3} \mathrm{~N}$ on the diastereoselectivity of this reaction.

Initial experiments to identify the best suited conditions for the reaction of the parent ammonium salt $\mathbf{6 a}(\mathrm{Ar}=$ $\mathrm{Ph}$ ) with benzaldehyde (2a) showed that a combination of $t$-BuOK as the base and THF as the solvent clearly outperforms other base/solvent systems. With these basic conditions set, we then further fine-tuned the reaction conditions and elucidated the scope of this transformation. Table
1 gives an overview of the most significant results obtained in a rather detailed screening of different reaction conditions and substrates. As shown in Table 1, entries 1-5, the amount of base as well as the reaction temperature play a significant role. For room temperature reactions it was found best to use three equivalents of $t$-BuOK which allowed for 69\% isolated yield of a 61:39 trans:cis mixture of $\mathbf{5 a}$ (Table 1 , entry 2 ), whereas a slightly higher temperature of $40{ }^{\circ} \mathrm{C}$ allowed us to obtain $\mathbf{5 a}$ in an excellent 93\% yield and a slightly higher trans selectivity (66:34) when using four equivalents of base (Table 1, entry 5). Noteworthy, larger or lower amounts of base reduced the yields significantly, either due to decomposition of the product or be-

Table 1 Syntheses of Epoxides 5 Using Trimethyl Amine Based Ammonium Salts 6

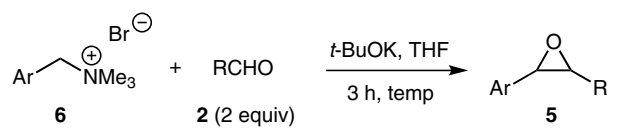

\begin{tabular}{|c|c|c|c|c|c|c|c|}
\hline Entry & $\mathrm{Ar}$ & $\mathrm{R}$ & 5 & $t$-BuOK (equiv) & Temp $\left({ }^{\circ} \mathrm{C}\right)$ & trans:cis ${ }^{\mathrm{a}}$ & Yield (\%) \\
\hline 1 & $\mathrm{Ph}$ & $\mathrm{Ph}$ & $5 a$ & 2 & 25 & $61: 39$ & 42 \\
\hline 2 & $\mathrm{Ph}$ & $\mathrm{Ph}$ & $5 a$ & 3 & 25 & 61:39 & 69 \\
\hline 3 & $\mathrm{Ph}$ & $\mathrm{Ph}$ & $5 a$ & 4 & 25 & $61: 39$ & 36 \\
\hline 4 & $\mathrm{Ph}$ & $\mathrm{Ph}$ & $5 a$ & 3 & 40 & $63: 37$ & 37 \\
\hline 5 & $\mathrm{Ph}$ & $\mathrm{Ph}$ & $5 a$ & 4 & 40 & $66: 34$ & 93 \\
\hline 6 & $\mathrm{Ph} / \mathrm{DABCO}$ salt & $\mathrm{Ph}$ & $5 b$ & 4 & 40 & $80: 20$ & 41 \\
\hline 7 & $\mathrm{Ph} / \mathrm{Et}_{3} \mathrm{~N}$ salt & $\mathrm{Ph}$ & $5 b$ & 4 & 40 & $89: 11$ & 31 \\
\hline 8 & $4-\mathrm{O}_{2} \mathrm{NC}_{6} \mathrm{H}_{4}$ & $\mathrm{Ph}$ & $5 b$ & 4 & 40 & n.d. ${ }^{c}$ & $0^{d}$ \\
\hline 9 & $4-\mathrm{O}_{2} \mathrm{NC}_{6} \mathrm{H}_{4}$ & $\mathrm{Ph}$ & $5 b$ & 3 & 25 & $95: 5$ & $19^{d}$ \\
\hline 10 & $4-\mathrm{F}_{3} \mathrm{CC}_{6} \mathrm{H}_{4}$ & $\mathrm{Ph}$ & $5 c$ & 4 & 40 & $>99: 1$ & 97 \\
\hline 11 & 4- $\mathrm{BrC}_{6} \mathrm{H}_{4}$ & $\mathrm{Ph}$ & $5 d$ & 4 & 40 & $91: 9$ & 89 \\
\hline 12 & 4- $\mathrm{FC}_{6} \mathrm{H}_{4}$ & $\mathrm{Ph}$ & $5 e$ & 4 & 40 & $55: 45$ & 94 \\
\hline 13 & $3-\mathrm{MeOC}_{6} \mathrm{H}_{4}$ & $\mathrm{Ph}$ & $5 f$ & 4 & 40 & $73: 27$ & 97 \\
\hline 14 & 4- $\mathrm{MeC}_{6} \mathrm{H}_{4}$ & $\mathrm{Ph}$ & $5 g$ & 4 & 40 & $47: 53$ & $52^{e}$ \\
\hline 15 & $\mathrm{Ph}$ & 4- $\mathrm{MeOC}_{6} \mathrm{H}_{4}$ & $5 h$ & 4 & 40 & $68: 32$ & 88 \\
\hline 16 & $\mathrm{Ph}$ & $2-\mathrm{MeOC}_{6} \mathrm{H}_{4}$ & $5 i$ & 4 & 40 & $41: 59$ & 83 \\
\hline 17 & $\mathrm{Ph}$ & $4-\mathrm{Me}_{2} \mathrm{NC}_{6} \mathrm{H}_{4}$ & $5 j$ & 4 & 40 & $86: 14$ & 99 \\
\hline 18 & $\mathrm{Ph}$ & 4- $\mathrm{MeC}_{6} \mathrm{H}_{4}$ & $5 g$ & 4 & 40 & $60: 40$ & 16 \\
\hline 19 & $\mathrm{Ph}$ & 4- $\mathrm{MeC}_{6} \mathrm{H}_{4}$ & $5 g$ & 3 & 25 & $64: 36$ & 66 \\
\hline 20 & $\mathrm{Ph}$ & $4-\mathrm{BrC}_{6} \mathrm{H}_{4}$ & $5 d$ & 4 & 40 & $60: 40$ & 90 \\
\hline 21 & $\mathrm{Ph}$ & $4-\mathrm{ClC}_{6} \mathrm{H}_{4}$ & $5 k$ & 4 & 40 & $64: 36$ & 81 \\
\hline 22 & $\mathrm{Ph}$ & 4- $\mathrm{NCC}_{6} \mathrm{H}_{4}$ & 51 & 4 & 40 & $50: 50$ & 26 \\
\hline 23 & 3- $\mathrm{MeOC}_{6} \mathrm{H}_{4}$ & 4- $\mathrm{BrC}_{6} \mathrm{H}_{4}$ & $5 m$ & 4 & 40 & $66: 34$ & 84 \\
\hline 24 & $4-\mathrm{F}_{3} \mathrm{CC}_{6} \mathrm{H}_{4}$ & 4- $\mathrm{BrC}_{6} \mathrm{H}_{4}$ & $5 n$ & 4 & 40 & $97: 3$ & 55 \\
\hline 25 & $\mathrm{Ph}$ & Cy & 50 & 4 & 40 & $62: 38$ & 8 \\
\hline
\end{tabular}

a Determined by ${ }^{1} \mathrm{H}$ NMR on the crude product.

${ }^{b}$ n.d. = not determined.

cIsolated yield of the mixture of both diastereomers.

${ }^{d}$ Epoxide $\mathbf{5 b}$ decomposition under the basic conditions.

e Partial oligomerization of $\mathbf{6 g}$ under the basic conditions. ${ }^{12}$ 
cause of insufficient reactivity when using less base. In addition, longer reaction times usually had no positive effect, even in those cases where conversion was slow.

To illustrate the different leaving group ability of trimethylamine compared to DABCO and triethylamine, we also used the analogous ammonium salts under the optimized conditions (Table 1, entries 6 and 7). These experiments clearly demonstrate the significantly higher yield using trimethylamine but also showed that with this more reactive system the diastereoselectivity slightly decreases, giving increasing amounts of the cis epoxides.

Having identified simple conditions that allowed for high yields within a short reaction time, we next tested a variety of differently substituted ammonium salts $\mathbf{6}$ (Table 1 , entries 8-14) and various aromatic aldehydes 2 (Table 1 , entries 15-24). Except in the case of electron-poor aryl groups (Table 1, entries 8 and 9) and/or electron-poor aryl aldehydes (Table 1, entry 22), for which $\mathbf{2}$ and $\mathbf{5}$ are prone to decomposition under the basic conditions, a variety of differently substituted aryl groups are well accepted in this reaction. Yields for epoxides $\mathbf{5}$ starting from electron-rich and electron-neutral substrates were equally high, apart for $\mathbf{5 g}$ synthesized from ammonium salt $\mathbf{6 g}$ (Table 1 , entry 14 ), which tends to oligomerize under the basic reaction conditions. ${ }^{12}$ As expected, the diastereoselectivity strongly depends on the electronic properties of the ammonium salt, with more stabilized ylides (obtained from 6 with electronpoorer aryl groups) gave higher trans selectivities. The opposite (but less pronounced) trend was observed by changing the nature of the aldehyde $\mathbf{2}$. Hereby, less reactive electron-rich aryl groups (i.e., Table 1, entries 15 and 17) give a higher trans selectivity than electron poorer ones (Table 1 , entry 20). Unfortunately, using cyclohexane carbaldehyde as the acceptor mainly resulted in decomposition, giving only minute amounts of the corresponding epoxide $\mathbf{5 0}$ (Table 1 , entry 25 ).

In order to investigate the origin of the observed better yield and lower diastereoselectivity using the trimethylamine-based ylide, as compared to DABCO, quinuclidine, and $\mathrm{Et}_{3} \mathrm{~N}$ derivatives, we carried out DFT calculations. We have computed the free energy profile of the reaction of $\mathrm{PhCHNMe}_{3}$ ylide with benzaldehyde at the B3LYP-D3/6$311+G^{* *}($ DCM $) / /$ B $3 L Y P / 6-31 G^{*}($ DCM $)$ level of theory (Table 2 and Figure 1). ${ }^{13}$ For purpose of comparison with Aggarwal's results, we also considered DABCO and quinuclidine derivatives. ${ }^{5 c}$

Our calculations are in good agreement with the previously predicted (partial) reversibility of betaine formation in reaction of quinuclidine-based ylide and the less or nonreversible addition step in the case of $\mathrm{Me}_{3} \mathrm{~N}$ and DABCO derivatives. ${ }^{14}$ While for trimethylamine-based ylides this reduced reversibility in betaine formation can be accounted for by a better leaving group ability (see free energy barri-

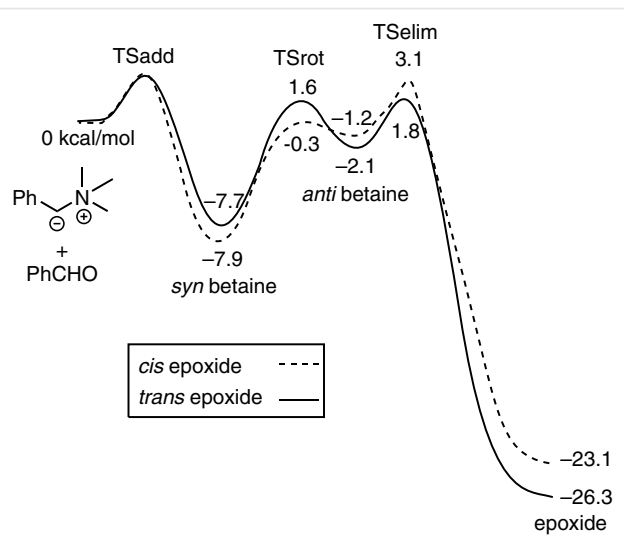

Figure 1 Calculated free energy profile $(\mathrm{kcal} / \mathrm{mol})$ for the epoxidation reaction between $\mathrm{PhCHNMe}_{3}$ ylide and benzaldehyde. See Supporting Information for the estimation of free energy barrier to addition.

ers from anti-betaine in brackets in Table 2), for DABCO derivatives the main reason is in fact a more exothermic betaine formation.

Accordingly, the generally low diastereoselectivity observed in reaction of trimethylamine-based ylides can be accounted for by a less reversible addition step which is therefore the selectivity determining step. This latter involving no significant barrier, ${ }^{15}$ it is expected to occur with no (or very low) selectivity. Conversely, for quinuclidinebased ylides the addition is predicted to be (partially) reversible, meaning that selectivity must be determined at the elimination step, which explains the high preference for trans-epoxides in this case. ${ }^{5}$

The observed increase in trans diastereoselectivity with electron-withdrawing character of ylide substituents (see Table 1, entries 7-9) can be explained by their impact on the degree of reversibility of addition, and hence on the origin of the selectivity-determining step. Indeed, stabilization of the ylide by EWG increases addition reversibility because of a less exothermic betaine formation and an increased free energy barrier to elimination ${ }^{16}$ (Figure 2 ). In the case of EWG substitution, selectivity is thus determined at the elimination step, and the predicted relative higher stability of trans-TSelim over its cis isomer (by $1.9 \mathrm{kcal} / \mathrm{mol}$ for 4$\mathrm{F}_{3} \mathrm{CC}_{6} \mathrm{H}_{4} \mathrm{CHNMe}_{3}$ ylide) accounts for the observed high selectivity.

In terms of yield, the better results obtained for reaction of $\mathrm{Me}_{3} \mathrm{~N}$-based ylides, as compared to DABCO and quinuclidine derivatives, can be explained by the higher reactivity toward epoxidation of the former due to a better leaving group ability, which then decreases the occurrence of competitive degradation reactions. ${ }^{17}$

One very versatile strategy to carry out ylide-mediated epoxidations without the need of strong basic conditions relies on the use of diazo compounds as ylide precursors. This strategy is commonly used for sulfonium ylide mediat- 
Table 2 Computed Relative Free Energies (kcal/mol)

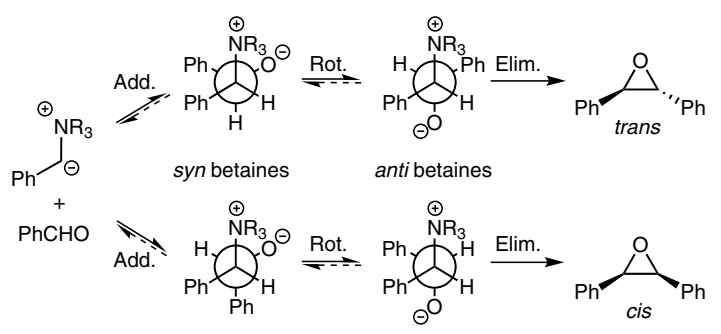

\begin{tabular}{|c|c|c|c|c|c|c|}
\hline \multirow[t]{2}{*}{$\mathrm{R}_{3} \mathrm{~N}=$} & \multicolumn{2}{|l|}{$\mathrm{Me}_{3} \mathrm{~N}$} & \multicolumn{2}{|l|}{ quinuclidine } & \multicolumn{2}{|l|}{ DABCO } \\
\hline & trans & cis & trans & cis & trans & cis \\
\hline TSadd & $--^{\mathrm{a}}$ & $-{ }^{\mathrm{a}}$ & $--^{a}$ & $--^{\mathrm{a}}$ & $-{ }^{a}$ & $-^{a}$ \\
\hline syn betaine & -7.7 & -7.9 & -8.8 & -9.1 & -15.8 & -15.9 \\
\hline TSrot & 1.6 & -0.3 & n.d. ${ }^{b}$ & n.d. ${ }^{b}$ & n.d. ${ }^{b}$ & n.d. ${ }^{b}$ \\
\hline anti betaine & -2.1 & -1.2 & -3.6 & -2.6 & -10.3 & -9.1 \\
\hline TSelim & $1.8(3.9)^{c}$ & $3.1(4.3)^{c}$ & $2.8(6.4)^{c}$ & $5.5(8.2)^{c}$ & $-4.2(6.1)^{c}$ & $-1.4(7.7)^{c}$ \\
\hline Epoxide $+\mathrm{R}_{3} \mathrm{~N}$ & -26.3 & -23.1 & -22.8 & -19.6 & -31.5 & -28.3 \\
\hline
\end{tabular}

a Betaine formation occurs without enthalpic barrier. ${ }^{15}$

${ }^{b}$ n.d. $=$ not determined.

c Free energy barrier from anti betaine reported in brackets.

ed epoxidations, where the diazo compound can be used to obtain ylides in situ upon reaction with a metal catalyst (usually Rh- or Cu-based) and a (catalytic amount of) sulfide as was impressively shown by Aggarwal's group. ${ }^{18}$ Interestingly, it was also shown that by changing from sulfonium to tellurium ylides, ${ }^{19}$ the corresponding alkenes are obtained instead of the epoxides. Much to our surprise (and to the best of our knowledge) no analogous reports for ammonium ylides have been reported so far. We thus tested

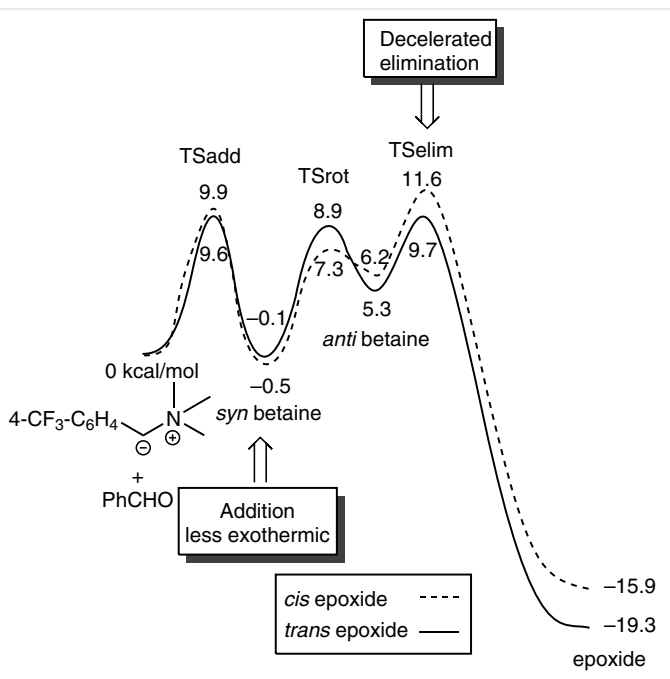

Figure 2 Effect of EWG substitution. Calculated free energy profile ( $\mathrm{kcal} / \mathrm{mol}$ ) for the epoxidation reaction between $4-\mathrm{F}_{3} \mathrm{CC}_{6} \mathrm{H}_{4} \mathrm{CHNMe}_{3}$ ylide and benzaldehyde. the feasibility of such a transformation by using phenyldiazomethane $\mathbf{7}$ in combination with $\mathrm{Rh}_{2}(\mathrm{OAc})_{4}$ and DABCO (8) as the amine component (Scheme 2). After thorough screening of different conditions, we found that such a reaction is possible in principle, albeit with low yield only. These low yields can mainly be attributed to rather pronounced side-reactions such as the dimerization of the diazo compound to stilbene derivatives or different carbene insertion products. Also, variations of the metal catalyst or the in situ generation of the diazo species under phasetransfer conditions (as reported previously ${ }^{18 \mathrm{~d}}$ ) were not beneficial. Attempts to use the amine component in a catalytic fashion also were not very successful. Thus, it can be concluded that, although possible, the use of diazo com-

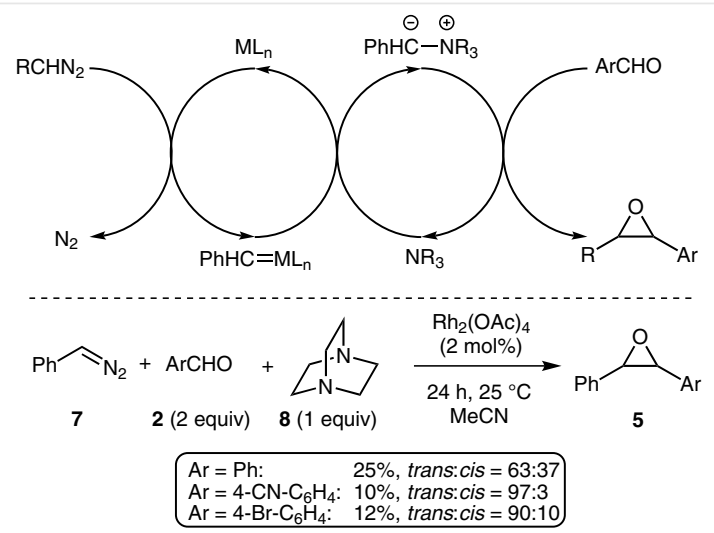

Scheme 2 Syntheses of epoxides $\mathbf{5}$ using phenyldiazomethane $\mathbf{7}$ as the ammonium ylide precursor 
pounds as ammonium ylide precursors for epoxide formations is not as effective as the comparable use for sulfonium ylide mediated reactions.

In conclusion, a high-yielding protocol for the synthesis of stilbene oxides using ammonium ylides has been developed. ${ }^{19,20}$ The nature of the amine leaving group plays a crucial role herein and it was found that trimethylamine gives significantly higher yields than DABCO or quinuclidine. The nature of the amine group also influences the diastereoselectivity in these reactions. A detailed DFT study allows understanding the different yields and selectivities when using different amine leaving groups and aryl substituents.

\section{Acknowledgment}

This work was supported by the Austrian Science Funds (FWF): Project No. P26387-N28. Computational resources have been provided by the supercomputing facilities of the Université catholique de Louvain (CISM/UCL) and the Consortium des Équipements de Calcul Intensif en Fédération Wallonie Bruxelles (CÉCI) funded by the Fond de la Recherche Scientifique de Belgique (F.R.S.-FNRS) under convention 2.5020.11. The NMR spectrometers used were acquired in collaboration with the University of South Bohemia $(\mathrm{CZ})$ with financial support from the European Union through the EFRE INTERREG IV ETC-AT-CZ program (project M00146, 'RERI-uasb'). RR is a Chercheur qualifié of the F.R.S.-FNRS.

\section{Supporting Information}

Supporting information for this article is available online at http://dx.doi.org/10.1055/s-0035-1562344.

\section{References and Notes}

(1) For selected reviews, see: (a) Aggarwal, V. K. In Comprehensive Asymmetric Catalysis; Jacobsen, E. N.; Pfaltz, A.; Yamamoto, H., Eds.; Springer: New York, 1999, Vol. 2 679. (b) McGarrigle, E. M.; Myers, E. L.; Illa, O.; Shaw, M. A.; Riches, S. L.; Aggarwal, V. K. Chem. Rev. 2007, 107, 5841.

(2) For seminal work on sulfur ylides, see: (a) Corey, E. J.; Chaykovsky, M. J. Am. Chem. Soc. 1962, 84, 867. (b) Corey, E. J.; Chaykovsky, M. J. Am. Chem. Soc. 1965, 87, 1353. (c) Johnson, A. W.; Lacount, R. B. Chem. Ind. 1958, 1440.

(3) For examples highlighting the use of sulfur ylides in epoxidation reactions, see: (a) Zhou, Y.-G.; Hou, X.-L.; Dai, L.-X.; Xia, L.-J.; Tang, M.-H.J. Chem. Soc., Perkin Trans. 1 1999, 77. (b) Zanardi, J.; Leriverend, C.; Aubert, D.; Julienne, K.; Metzner, P. J. Org. Chem. 2001, 66, 5620. (c) Aggarwal, V. K.; Hynd, G.; Picoul, W.; Vasse, J.-L. J. Am. Chem. Soc. 2002, 124, 9964. (d) Aggarwal, V. K.; Richardson, J. Chem. Commun. 2003, 2644. (e) Davoust, M.; Briere, J.-F.; Jaffres, P.-A.; Metzner, P. J. Org. Chem. 2005, 70, 4166. (f) Aggarwal, V. K.; Charmant, J. P. H.; Fuentes, D.; Harvey, J. N.; Hynd, G.; Ohara, D.; Picoul, W.; Robiette, R.; Smith, C.; Vasse, J.-L.; Winn, C. L. J. Am. Chem. Soc. 2006, 128, 2105. (g) Illa, O.; Arshad, M.; Ros, A.; McGarrigle, E. M.; Aggarwal, V. K. J. Am. Chem. Soc. 2010, 132, 1828. (h) Illa, O.; Namutebi, M.; Saha, C.; Ostovar, M.; Chen, C. C.; Haddow, M. F.; Nocquet-Thibault, S.; Lusi, M.; McGarrigle, E. M.; Aggarwal, V. K. J. Am. Chem. Soc. 2013, 135, 11951 .
(4) For ammonium ylide mediated cyclopropanations, see: (a) Gaunt, M. J.; Johansson, C. C. C. Chem. Rev. 2007, 107, 5596. (b) Johansson, C. C. C.; Bremeyer, N.; Ley, S. V.; Owen, D. R.; Smith, S. C.; Gaunt, M. J. Angew. Chem. Int. Ed. 2006, 45, 6024. (c) Papageorgiou, C. D.; Cubillo de Dios, M. A.; Ley, S. V.; Gaunt, M. J. Angew. Chem. Int. Ed. 2004, 43, 4641. (d) Bremeyer, N.; Smith, S. C.; Ley, S. V.; Gaunt, M. J. Angew. Chem. Int. Ed. 2004, 43, 2681. (e) Papageorgiou, C. D.; Ley, S. V.; Gaunt, M. J. Angew. Chem. Int. Ed. 2003, 42, 828.

(5) For benzylic ammonium ylide mediated epoxidations, see: (a) Kimachi, T.; Kinoshita, H.; Kusaka, K.; Takeuchi, Y.; Aoe, M.; Ju-ichi, M. Synlett 2005, 842. (b) Kinoshita, H.; Ihoriya, A.; Juichi, M.; Kimachi, T. Synlett 2010, 2330. (c) Robiette, R.; Conza, M.; Aggarwal, V. K. Org. Biomol. Chem. 2006, 4, 621. (d) Xiao, X.; Lin, D.; Tong, S.; Mo, H. Synlett 2011, 2823.

(6) For cyano-stabilized ammonium ylide mediated epoxidations, see: (a) Jonczyk, A.; Konarska, A. Synlett 1999, 1085. (b) Kowalkowska, A.; Sucholbiak, D.; Jonczyk, A. Eur. J. Org. Chem. 2005, 925. (c) Alex, A.; Larmanjat, B.; Marrot, J.; Couty, F.; David, O. Chem. Commun. 2007, 2500.

(7) For amide-stabilized ammonium ylide mediated epoxidations, see: (a) Waser, M.; Herchl, R.; Müller, N. Chem. Commun. 2011, 47, 2170. (b) Herchl, R.; Stiftinger, M.; Waser, M. Org. Biomol. Chem. 2011, 9, 7023. (c) Pichler, M.; Novacek, J.; Robiette, R.; Poscher, V.; Himmelsbach, M.; Monkowius, U.; Müller, N.; Waser, M. Org. Biomol. Chem. 2015, 13, 2092. (d) Novacek, J.; Roiser, L.; Zielke, K.; Robiette, R.; Waser, M. Chem. Eur. J. 2016, DOI: 10.1002/chem.201602052.

(8) For ammonium ylide mediated aziridinations, see: (a) Yadav, L. D. S.; Kapoor, R.; Garima, Synlett 2009, 3123. (b) Aichhorn, S.; Gururaja, G. N.; Reisinger, M.; Waser, M. RSC Adv. 2013, 3, 4552.

(9) Aggarwal, V. K.; Harvey, J. N.; Robiette, R. Angew. Chem. Int. Ed. 2005, 44, 5468

(10) For a recent report on selenium ylide mediated epoxidations, see: Banach, A.; Scianowski, J.; Uzarewicz-Baig, M.; Wojtczak, A. Eur. J. Org. Chem. 2015, 3477.

(11) Ylide addition onto the aldehyde occurs without enthalpic barrier and thus no significant selectivity is expected for this step.

(12) Winberg, H. E.; Fawcett, F. S.; Mochel, W. E.; Theobald, C. W. J. Am. Chem. Soc. 1960, 82, 1428.

(13) Computations have been carried out at the B3LYP-D3/6$311+\mathrm{G}(\mathrm{d}, \mathrm{p}) / / \mathrm{B} 3 \mathrm{LYP} / 6-31 \mathrm{G}^{*}$ level of theory, including a continuum description of dichloromethane solvent for both the geometry optimization and the single-point energy calculation using Jaguar, version 8.5; Schrodinger, Inc.: New York, 2014. Thermal and entropic contributions to free energy were computed by performing frequency calculations at the B3LYP/6-31G (d) level of theory using the fine DFT grid within Jaguar. See ESI for full computational details and data.

(14) In the earlier computational study (ref. 5c) only electronic energies were obtained, but no entropic and thermal contributions were included.

(15) Betaine formation occurs without enthalpic barrier. A set of constrained geometry optimization at successively smaller values of the $\mathrm{C}-\mathrm{C}$ distance showed that the interaction between reactants is uniformly attractive. The free-energy barrier of a diffusion controlled reaction can, however, be estimated at 3.7 $\mathrm{kcal} / \mathrm{mol}$ in THF at $40{ }^{\circ} \mathrm{C}$ (see Supporting Information for details).

(16) Robiette, R.; Trieu-Van, T.; Aggarwal, V. K.; Harvey, J. N. J. Am. Chem. Soc. 2016, 138, 734. 
(17) In contrast to DABCO, quinuclidine, or triethylammonium salts the herein used trimethylammonium salts cannot undergo Hofmann elimination reactions. A possible side reaction that sometimes occurs with all these ylides is the Stevens rearrangement: Maeda, Y.; Sato, Y. J. Chem. Soc., Perkin Trans. 1 1997, 1491.

(18) For seminal studies, see: (a) Aggarwal, V. A.; Abdel-Rahman, H.; Jones, R. V. H.; Lee, H. Y.; Reid, B. D. J. Am. Chem. Soc. 1994, 116, 5973. (b) Aggarwal, V. A.; Abdel-Rahman, H.; Jones, R. V. H.; Standen, M. C. H. Tetrahedron Lett. 1995, 36, 1731. (c) Aggarwal, V. A.; Abdel-Rahman, H.; Fan, L.; Jones, R. V. H.; Standen, M. C. H. Chem. Eur. J. 1996, 2, 1024. (d) Aggarwal, V. K.; Alonso, E.; Bae, I.; Hynd, G.; Lydon, K. M.; Palmer, M. J.; Patel, M.; Porcelloni, M.; Richardson, J.; Stenson, R. A.; Studley, J. R.; Vasse, J.-L.; Winn, C. L. J. Am. Chem. Soc. 2003, 125, 10926.

(19) Zhu, S.; Xing, C.; Pang, W.; Zhu, S. Tetrahedron Lett. 2006, 47, 5897.

(20) General Epoxidation Procedure

Ammonium salt 6 ( 1 equiv) was suspended in $\operatorname{dry} \operatorname{THF}(0.05 \mathrm{M})$ and stirred at $40{ }^{\circ} \mathrm{C}$. $t$-BuOK ( 4 equiv) was added, and the mixture was stirred vigorously. After $10 \mathrm{~min}, 2$ equiv of aldehyde 2 were added, and the mixture was stirred for $3 \mathrm{~h}$ at $40^{\circ} \mathrm{C}$. The reaction was then quenched by addition of a half-saturated $\mathrm{NaCl}$ solution. After phase separation, the aqueous phase was extracted three times with $\mathrm{CH}_{2} \mathrm{Cl}_{2}$, and the combined organic phases were dried with $\mathrm{Na}_{2} \mathrm{SO}_{4}$ and evaporated to dryness. Purification by column chromatography (gradient of heptanes and EtOAc) gave the corresponding epoxides in the reported yields as a mixture of diastereomers.

Compound 5a: Obtained in 93\% (trans/cis $=66: 34$ ) on a 0.5 mmol scale as a white solid. Analytical data match those reported previously. ${ }^{5,21}$

\section{Selected Data}

${ }^{1} \mathrm{H}$ NMR (300 MHz, $\left.\delta, \mathrm{CDCl}_{3}, 298 \mathrm{~K}\right)$ :trans isomer: $3.94(\mathrm{~s}, 2 \mathrm{H})$, 7.36-7.49 (m, $5 \mathrm{H})$; cis isomer: $4.42(\mathrm{~s}, 2 \mathrm{H}), 7.18-7.28(\mathrm{~m}, 5 \mathrm{H})$ ppm. ESI-HRMS: $m / z$ calcd for $\mathrm{C}_{14} \mathrm{H}_{12} \mathrm{O}: 197.0961[\mathrm{M}+\mathrm{H}]^{+}$; found: 197.0961.

(21) Robinson, M. W. C.; Davies, A. M.; Buckle, R.; Mabbett, I.; Taylor, S. H.; Graham, A. E. Org. Biomol. Chem. 2009, 7, 2559. 